\title{
In Vitro Growth of Enterococci of Bovine Origin in Bovine Mammary Secretions from Various Stages of Lactation ${ }^{1}$
}

\author{
C. S. Petersson-Wolfe, S. L. Wolf, and J. S. Hogan ${ }^{2}$ \\ Department of Animal Sciences, The Ohio State University, Ohio Agricultural Research and Development Center, Wooster 44691
}

\begin{abstract}
In vitro growth responses of Enterococcus faecium and Enterococcus faecalis were tested in cell-free, fatfree bovine mammary secretions. Mammary secretions were collected during the dry period, and during early, late, and extended lactation. Sixty-three enterococcal isolates from aseptically collected bovine quarter milk samples and bedding samples from a commercial dairy herd were tested. Isolates from bovine quarter milk samples originated from mammary glands with clinical mastitis, cows with composite somatic cell score $>4$, postpartum milk samples, or from routine milk samples submitted to a mastitis diagnostic laboratory. Source of enterococcal isolates and the species significantly contribute to the ability of organisms to multiply in mammary secretions from various stages of lactation. Isolates collected from milk samples of the commercial herd and isolates from milk submitted to a mastitis diagnostic lab did not display enhanced growth in mammary secretions compared with isolates from bedding. Growth responses of $E$. faecalis were greater than those for $E$. faecium in secretions collected during the dry period, late lactation, and extended lactation. Bacterial growth did not differ between enterococcal species in mammary secretion collected from cows in early lactation. Differences in bacterial growth between $E$. faecalis and $E$. faecium in mammary secretions may indicate differences between species in susceptibility of mammary glands during the lactation cycle.
\end{abstract}

Key words: Enterococcus spp., mammary secretions, in vitro growth

\section{INTRODUCTION}

Bacteria in the genus Enterococcus are ubiquitously found in the environment (Devriese and Pot, 1995;

\footnotetext{
Received February 5, 2007.

Accepted April 30, 2007.

${ }^{1}$ Salaries and research support were provided by state and federal funds appropriated to the Ohio Agricultural Research and Development Center, The Ohio State University; manuscript no. 19/07/AS.

${ }^{2}$ Corresponding author: hogan.4@osu.edu
}

Franz et al., 2003), inhabit intestines of warm-blooded animals (Devriese et al., 1992), are indicators of fecal pollution in water (Godfree et al., 1997), and are a leading cause of nosocomial infections (NNIS Report, 1997). Distributed through environmental isolates and concentrated among isolates responsible for nosocomial infections are intrinsic resistance genes to many broadspectrum antibiotics and acquired resistance genes to vancomycin (Huycke et al., 1998; Hayes et al., 2004). The potential transfer of enterococci from these common sources to food animals and finished products has given rise to concerns about their role in public health. In addition, enterococci cause many economically important veterinary diseases including bovine mastitis (Devriese et al., 1992). Enterococcus species have commonly been included in the grouping of environmental streptococci when IMI have been reported for individual herds or survey results (Hogan et al., 1989). Estimates suggest that 24 to $30 \%$ of IMI classified as environmental streptococcal infections are actually caused by enterococci (McDonald and McDonald, 1976; Devriese et al., 1999). The enterococcal species most commonly isolated from bovine mastitis were Enterococcus faecalis and Enterococcus faecium (Sobiraj et al., 1997; Devriese et al., 1999). Past reports have assumed that the primary sources of enterococci for IMI and growth responses in mammary secretion were consistent with those of streptococci (Todhunter et al., 1985, 1995). Developing management strategies to control mastitis caused by Enterococcus spp. will require an understanding of the epidemiology and etiology of the Enterococcus species that cause IMI.

Growth in mammary secretion is required to permit the colonization and establishment of IMI in vivo. Previous in vitro studies have examined growth characteristics of various types of bacteria including Corynebacterium bovis (Oliver and Juneja, 1990), Streptococcus spp. (Todhunter et al., 1985), Staphylococcus spp. (Oliver et al., 1990), and gram-negative bacteria (Lohuis et al., 1990; Todhunter et al., 1990; Lin et al., 1998) in mammary secretions. These in vitro growth studies have provided valuable insight into the capability of mastitis pathogens to replicate in mammary secretions, devel- 
oped the understanding of the changes in susceptibility of mammary glands to colonization during various stages of lactation, and provided baseline information for testing means to alter the mammary environment to reduce bacterial multiplication. Despite the potentially adverse impact of enterococci on udder health and, consequently, public health, little is known about the ability of enterococcal species to replicate in mammary secretions throughout the lactation cycle. Therefore, the objective of the current study was to compare growth responses of $E$. faecium and $E$. faecalis isolates of bovine origin in mammary secretion from various stages of lactation in an in vitro model.

\section{MATERIALS AND METHODS}

\section{Origin of Bacterial Isolates}

Sixty-three enterococcal isolates were collected for testing from April 2004 to October 2004. Forty-five isolates were from a commercial herd of approximately 1,200 lactating cows managed in dry-lot corrals with cooling shades. Eighteen isolates were from quartermilk samples submitted by 18 different herds to a mastitis diagnostic laboratory (Ohio Agricultural Research and Development Center Mastitis Lab, Wooster). The 2 enterococcal species included in this study were $E$. faecium $(\mathrm{n}=47)$ and $E$. faecalis $(\mathrm{n}=16)$. Enterococcus faecium were isolated from aseptically collected quarter-milk samples of cows with a composite milk SCS $>4$ (i.e., high SCC milk, $\mathrm{n}=10$ ) within $2 \mathrm{wk}$ following DHI testing, quarters with clinical mastitis before antibiotic therapy $(\mathrm{n}=10)$, postpartum milk within $3 \mathrm{~d}$ after parturition $(n=10)$, dried manure bedding collected monthly during the sample period $(\mathrm{n}=10)$, and milk submitted to a mastitis diagnostic laboratory $(\mathrm{n}=7)$. Enterococcus faecalis were isolated from only 2 sources: postpartum milk $(\mathrm{n}=5)$ and milk submitted to a mastitis diagnostic laboratory $(\mathrm{n}=11)$. Of the 53 isolates originating from milk, 49 cows and 51 quarters were represented.

Isolation from Milk Samples. All milk samples were frozen at $-20^{\circ} \mathrm{C}$ after collection and thawed at room temperature before primary isolation of bacteria. Milk was plated on tryptic soy agar (Becton, Dickinson and Company, Sparks, MD) containing $5 \%$ bovine blood and $0.1 \%$ esculin (MP Biomedicals LLC, Aurora, OH). Primary isolation plates were incubated aerobically at $37^{\circ} \mathrm{C}$ for $48 \mathrm{~h}$. Gram-positive, catalase-negative cocci that hydrolyzed esculin and grew in the presence of $6.5 \% \mathrm{NaCl}$ were presumptively identified as enterococci. Only the presumptively identified enterococcus isolates identified by the API 20 STREP system (bioMérieux Industry, Hazelwood, MO) as either E. faecium or
$E$. faecalis with greater than $95 \%$ confidence were tested for growth in mammary secretions.

Isolation from Bedding. Twenty-five grams of composite bedding sample was collected from corrals housing lactating cows every 4 wk during the collection period. Bacteria were isolated in bedding by adding $10 \mathrm{~g}$ of sample to $90 \mathrm{~mL}$ of sterile PBS and mixing the solution for $40 \mathrm{~s}$ in a stomacher (Stomacher Lab-Blender 400, Tekmar Co., Cincinnati, OH). Serial dilutions of the liquid phase in sterile PBS were plated on the surface of kanamycin esculin azide agar (Oxoid Ltd., Basingstoke, UK) for selection and differentiation of enterococci. Serial dilutions plated were $1: 10^{2}$ to $1: 10^{6}$. Inoculated plates were incubated for $24 \mathrm{~h}$ at $37^{\circ} \mathrm{C}$. Random colonies with black pigment and haloes of esculin hydrolysis were selected and plated on trypticase soy agar containing $5 \%$ bovine blood and $0.1 \%$ esculin. Presumptive identification, testing with the API 20 STREP system, and criteria for inclusion were the same as isolates from milk samples.

\section{Mammary Secretions}

Composite mammary secretions were obtained and pooled from 20 cows $(25 \mathrm{~mL} / \mathrm{cow})$ at the Ohio Agricultural Research and Development Center, Krauss Dairy Center (Wooster) for each of 4 stages of lactation. Mammary secretions were collected only from cows that did not have clinical mastitis and were not treated with antibiotics for $21 \mathrm{~d}$ before sampling. The secretions included nonlactating (dry cow, collected on d 21 of involution), early lactation (34.9 DIM, range 3 to $90 \mathrm{~d}$ ), late lactation (226.4 DIM, range 201 to $245 \mathrm{~d}$ ), and extended lactation (346.1 DIM, range 318 to 420 d). Secretions were centrifuged $\left(48,000 \times g, 1 \mathrm{~h}, 4^{\circ} \mathrm{C}\right)$ and cell-free, fat-free supernatant was decanted. The supernatant was passed through a series of filters (Millipore Corporation, Bedford, MA) ending with a $0.4-\mu \mathrm{m}$ filter to achieve sterility. Aliquoted secretions were stored $\left(-20^{\circ} \mathrm{C}\right)$ until later use.

\section{In Vitro Bacterial Growth Assay}

In vitro growth assays for enterococcal isolates were as described by Todhunter et al. (1985) with a few exceptions. Each enterococcal isolate was cultured in tryptic soy broth (Becton Dickinson) for $18 \mathrm{~h}$ at $37^{\circ} \mathrm{C}$. The tryptic soy broth cultures were centrifuged $(5,000 \times g, 20$ min) and supernatant was decanted. Bacterial pellets were resuspended in sterile PBS and adjusted to approximately $10^{4} \mathrm{cfu} / \mathrm{mL}$. Growth of enterococci in sterile mammary secretions was performed in 96-well microtiter plates (Dynatech Laboratories, Inc., Alexandria, VA). For each $260-\mu \mathrm{L}$ capacity well in the microtiter 
plate, $10 \mu \mathrm{L}$ of bacterial suspension was inoculated into $240 \mu \mathrm{L}$ of mammary secretion. Each micotiter plate facilitated duplicate assays of 12 isolates in each of the 4 mammary secretions. Microtiter plates were covered and aerobically incubated in a humid atmosphere $\left(37^{\circ} \mathrm{C}, 18 \mathrm{~h}\right)$. Following incubation, cultures were serially diluted in PBS and four $10-\mu \mathrm{L}$ spots plated on the surface of a tryptic soy agar plate for incubation at $37^{\circ} \mathrm{C}$ for $24 \mathrm{~h}$. Ferric ammonium citrate $(0.05 \%$; Fisher Scientific Co., Pittsburgh, PA) was added to the agar plate to facilitate the counting of enterococcal isolates. Assays were replicated on separate days for each isolate. A difference between replicated assays of $\leq 0.5 \mathrm{cfu}$ $\log _{10} / \mathrm{mL}$ was considered valid.

\section{Statistical Analyses}

All data were stored in a computer database (Microsoft Access 2000 for Windows; Microsoft Corporation, Redmond, WA), linked by a unique bacterial identifier. The analysis of bacterial growth was performed using the MIXED procedure in SAS (SAS System for Windows, Version 9.1, SAS Institute Inc., Cary, NC). All variables were evaluated for normality. Bacterial growth was expressed as colony-forming units per milliliter, $\log _{10}\left(\mathrm{cfu} / \mathrm{mL}, \log _{10}\right)$. The outcome variable for bacterial growth was created by subtracting the count at inoculation from the final count following incubation; this variable was termed "log change in growth." Independent variables offered into the model included bacterial species ( $E$. faecium and $E$. faecalis), mammary secretion (dry, early, late, and extended), and isolate source (bedding, clinical mastitis, postpartum milk, high SCC milk, and milk submitted to a mastitis diagnostic laboratory). All variables were entered into the model and manually removed by backwards elimination based on the significance of the $P$-value $(P<0.05)$, from highest to lowest until all variables in the model were significant. All biologically plausible 2 -way interaction terms were tested for significance. Differences in least squares means and standard errors were determined for significant variables. To adjust for multiple comparisons within each model, Tukey's adjusted $P$ values were calculated for each variable. Results were considered significant at $P<0.05$, unless otherwise stated. Once the final model was chosen, the residuals were checked for homoscedasticity, outliers, leverage cases, and normal distribution.

\section{RESULTS}

Source of bacterial isolate and the interaction of bacterial species and type of mammary secretion significantly contributed to the variation of log change in growth (Table 1). Holding other variables constant, growth responses for isolates originating from bedding, postpartum milk, and milk submitted to a mastitis diagnostic laboratory were greater in mammary secretions than for those isolates from clinical mastitis and high SCC milk (Figure 1). The interaction of bacterial species and type of mammary secretion suggested that $E$. faecalis growth responses were consistent among mammary secretions, whereas growth responses of $E$. faecium were more variable among secretions (Figure 2 ). Growth responses for $E$. faecalis isolates were greater in dry-cow, late-lactation, and extended-lactation secretions compared with those for E. faecium. Growth responses in early-lactation secretions were not different between the species. Within $E$. faecalis isolates, no differences in growth responses were seen among bacterial sources (Figure 3). However, growth responses of $E$. faecium isolates differed among bacterial sources in dry-cow and extended-lactation secretions (Figure 4). Dry-cow and extended-lactation secretions enhanced the growth responses of $E$. faecium isolates originating from bedding, postpartum milk, and milk submitted to a mastitis diagnostic laboratory compared with isolates originating from high SCC milk and clinical mastitis.

\section{DISCUSSION}

The infectious disease process for bovine mastitis involves bacteria breaching the teat canal, replicating in the mammary secretion, and evading innate and induced host defenses (National Mastitis Council, 1996). The neutrophil response is well established as the primary cellular defense mechanism for elimination of many pathogens from the bovine mammary gland (Sordillo et al., 1997; Paape et al., 2003). However, rate of replication and maximum number of bacteria per milliliter of secretion before or during the neutrophil response were positively associated with the severity of mastitis (Hogan et al., 1995; Bannerman et al., 2004). Mammary secretions tested in the present study were collected and prepared as in previous trials to establish an in vitro assay to estimate the rate of replication in secretion without the variable of cellular response (Todhunter et al., 1985; Oliver and Juneja, 1990). The presence and concentration of several soluble innate host defenses against bacterial multiplication change with the functional status of the mammary gland. Lactoferrin, immunoglobulin, lactoperoxidase, complement, and lysozyme are all soluble components of mammary secretions that affect the rate of multiplication of bacteria dependent upon the stage of lactation (reviewed by Sordillo et al., 1997). The current experiment was performed to discover baseline information relative 
Table 1. Final model for log change in growth using the mixed model procedure in SAS for Enterococcus faecium and Enterococcus faecalis isolates $(\mathrm{n}=63)$ from 5 sources inoculated into cell-free, fat-free mammary secretion from 4 stages of lactation ${ }^{1}$

\begin{tabular}{lcrr}
\hline & $\begin{array}{c}\text { Estimate } \\
\left(\mathrm{cfu} / \mathrm{mL}, \log _{10}\right)\end{array}$ & $\mathrm{SE}$ & $P>|\mathrm{t}|$ \\
Parameter & & & \\
\hline Bacterial source $^{2}$ & 1.04 & 0.24 & 0.0002 \\
$\quad$ Bedding vs. clinical mastitis & 1.09 & 0.24 & $<0.0001$ \\
Bedding vs. high SCC milk & 1.15 & 0.23 & $<0.0001$ \\
Postpartum milk vs. clinical mastitis & 1.21 & 0.23 & $<0.0001$ \\
Postpartum milk vs. high SCC milk & 1.08 & 0.24 & $<0.0001$ \\
OARDC milk vs. clinical mastitis & 1.13 & 0.24 & $<0.0001$ \\
OARDC milk vs. high SCC milk & & & $<0.0001$ \\
Bacterial species $\times$ mammary secretion & & & 0.0015 \\
E. faecium vs. E. faecalis & -2.01 & 0.34 & $<0.0001$ \\
Dry-cow secretion & -1.34 & 0.34 & 0.33 \\
Late-lactation secretion & -1.71 & & \\
Extended-lactation secretion & & & \\
\hline
\end{tabular}

${ }^{1}$ Log change in growth is defined as the subtraction of inoculated count (cfu/mL, $\log _{10}$ ) from incubated count $\left(\mathrm{cfu} / \mathrm{mL}, \log _{10}\right)$. Values shown are differences in least squares means and standard errors.

${ }^{2}$ Bacterial isolates originated from bovine mammary glands and bedding samples from a commercial dairy herd; isolates from bovine mammary glands originated from clinical mastitis events, milk from cows with composite somatic cell score $>4$ (high SCC milk), postpartum milk samples or from routine milk samples submitted to the Ohio Agricultural Research and Development Center (OARDC) Mastitis Laboratory (Wooster).

${ }^{3}$ Sterile mammary secretions tested included dry-cow secretion, early-lactation, late-lactation, and extended lactation secretions.

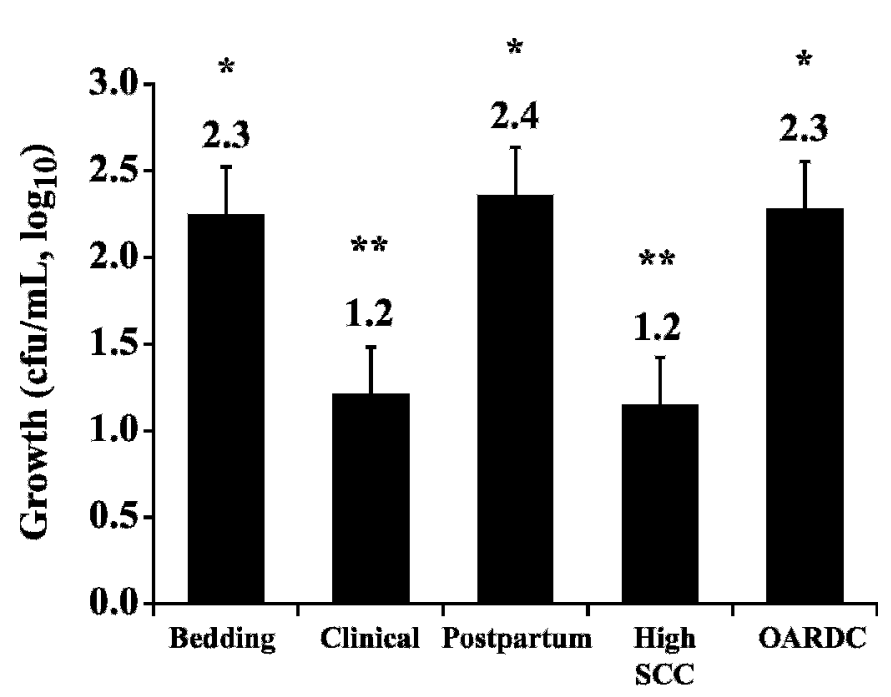

Source of isolate

Figure 1. Log change in growth (subtraction of inoculated count in cfu/mL, $\log 10$ from incubated count) of Enterococcus faecium and Enterococcus faecalis isolates from 5 sources in cell-free, fat-free bovine mammary secretions. Values shown are mean \pm SE. Sources of bacterial isolates were bovine mammary glands and bedding samples (bedding, $\mathrm{n}=10$ ) from a commercial dairy herd; isolates from bovine mammary glands originated from clinical mastitis events (clinical, $\mathrm{n}=10$ ); cows with composite SCS $>4$ (high SCC, $\mathrm{n}=10$ ); postpartum milk samples (postpartum, $\mathrm{n}=15$ ); and from routine milk samples submitted to the Ohio Agricultural Research and Development Center (OARDC, $\mathrm{n}=18$ ) mastitis laboratory (Wooster). ***Sources with the same symbol are not different $(P>0.05)$. to susceptibility of the mammary glands to colonization by enterococci based on in vitro growth in mammary secretions using an established in vitro assay system.

The ubiquitous nature of Enterococcus species in the environment (Devriese et al., 1992; Weaver et al., 2005) virtually assures mammary contact with potential pathogens of this genus. A variable of interest in the current study was to determine the impact of source of isolate on growth in mammary secretions. The majority

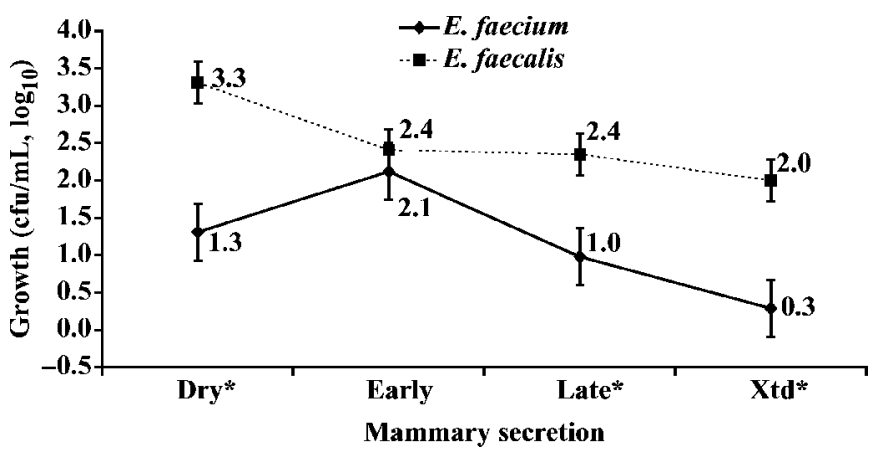

Figure 2. Log change in growth (subtraction of inoculated count in cfu/mL, $\log _{10}$ from incubated count) of Enterococcus faecium and Enterococcus faecalis isolates in cell-free, fat-free bovine mammary secretions from 4 stages of lactation. Values shown are mean $\pm \mathrm{SE}$. Types of mammary secretion were dry-cow secretion (d 21 of involution), early-lactation secretion $(<100 \mathrm{DIM})$, late-lactation secretion (200 to 250 DIM), and extended-lactation secretion (Xtd, >300 DIM). Asterisk $(*)$ indicates that growth between species was significantly different $(P<0.05)$. 


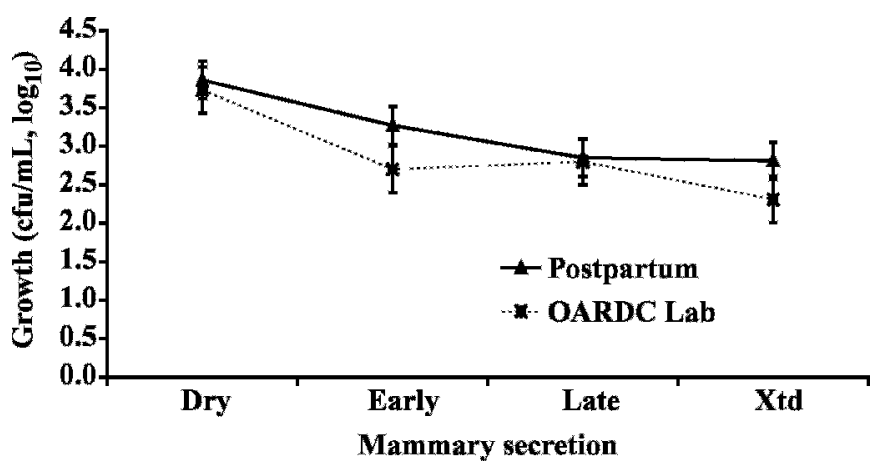

Figure 3. Log change in growth (subtraction of inoculated count in cfu $/ \mathrm{mL}, \log _{10}$ from incubated count) of Enterococcus faecalis isolates from 2 sources in cell-free, fat-free bovine mammary secretions from 4 stages of lactation. Values shown are mean \pm SE. Sources of bacterial isolates were postpartum milk samples (postpartum, $\mathrm{n}=5$ ) and from routine milk samples submitted to the Ohio Agricultural Research and Development Center (OARDC, $\mathrm{n}=11$ ) mastitis laboratory (Wooster). Types of mammary secretion were dry-cow secretion (d 21 of involution), early-lactation secretion ( $<100$ DIM), late-lactation secretion (200 to $250 \mathrm{DIM}$ ), and extended-lactation secretion (Xtd, $>300$ DIM).

of isolates were collected from quarter milk samples and bedding samples from a single herd. The assumption prior to the trial was that isolates from quarters with clinical mastitis or subclinical mastitis would be more adapted to multiply in mammary secretion than would enterococcal isolates collected from the herd's environment. In fact, the inverse was observed. Isolates collected from bedding had growth responses similar to

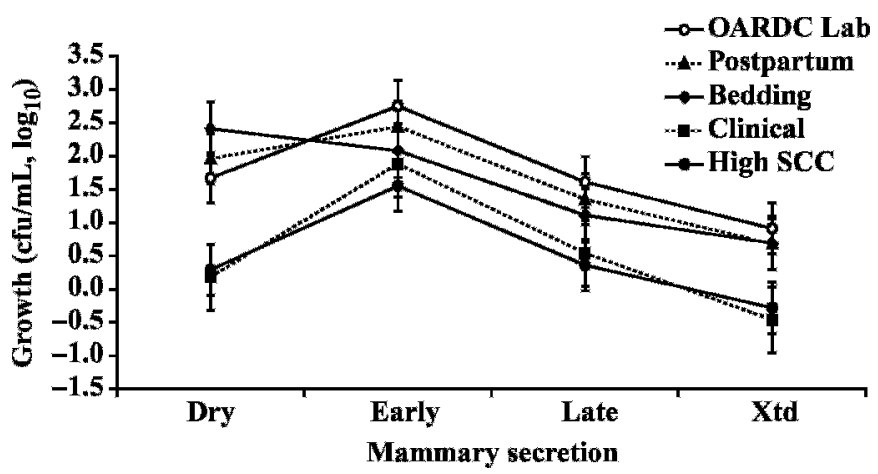

Figure 4. Log change in growth $\dagger$ of Enterococcus faecium isolates from 5 sources in cell-free, fat-free bovine mammary secretions from 4 stages of lactation. Values shown are mean \pm SE. Sources of bacterial isolates were bovine mammary glands and bedding samples from a commercial dairy herd (bedding, $\mathrm{n}=10$ ); isolates from bovine mammary glands originated from clinical mastitis events (clinical, $\mathrm{n}=$ 10); cows with composite SCS $>4$ (high SCC, $\mathrm{n}=10$ ); postpartum milk samples (postpartum, $\mathrm{n}=10$ ); and from routine milk samples submitted to the Ohio Agricultural Research and Development Center (OARDC, $\mathrm{n}=7$ ) mastitis laboratory (Wooster). Types of mammary secretion were dry-cow secretion (d 21 of involution), early-lactation secretion (<100 DIM), late-lactation secretion (200 to $250 \mathrm{DIM})$, and extended-lactation secretion (Xtd, >300 DIM). or greater than isolates from mammary glands of the commercial herd and isolates from milk submitted to a mastitis diagnostic lab. Therefore, isolates from glands displaying clinical signs or elevated SCC did not have a selective advantage over environmental isolates to replicate in the various mammary secretions used in this study. Isolates that have the capability of causing visible changes to the milk and an elevated SCC may contain genetic factors contributing to enhanced virulence in the gland other than those responsible for rapid growth in the test media. Therefore, rate of growth in the assay system may not be an adequate predictor of pathogenicity. Alternatively, enterococci may be environmental, opportunistic pathogens to the mammary gland without prerequisite virulence factors or traits of pathogenicity. Coliforms have been described similarly when virulence factors commonly ascribed to coliform isolates from other diseases were not consistently observed in isolates from mammary glands (Burvenich et al., 2003; Hogan and Smith, 2003).

The enterococcal species tested, $E$. faecalis and $E$. faecium, were those previously reported as the predominant species in mastitis prevalence studies (Devriese et al., 1999; Tenhagen et al., 2006). Surveys have shown that the overall prevalence of enterococcal IMI was greater during the early dry period compared with lactation (Todhunter et al., 1995), and prevalence did not differ in cows $\leq 50$ DIM and cows $\geq 250$ DIM (Tenhagen et al., 2006). Secretion samples used in the current trial were collected at times comparable to the sample points in these surveys to include the early nonlactating period, early lactation, late lactation, and extended lactation. Bacterial growth of $E$. faecalis in secretion from nonlactating glands was greater than in secretions sampled during lactation. These results are similar to an earlier trial using a single type strain of $E$. faecalis (Todhunter et al., 1985) and comparable to the highest rate of IMI by Enterococcus spp. occurring during the first half of dry period (Todhunter et al., 1995). In contrast, bacterial growth of $E$. faecium was reduced in nonlactating secretion compared with secretion collected during early lactation. Bacterial growth of $E$. faecalis did not differ among secretions collected during lactation, whereas growth of $E$. faecium was enhanced in early lactation secretion compared with late- and extended-lactation secretions. Results of the current trial revealed that the 2 species differed in growth responses depending upon the stage of lactation when secretions were collected. Enterococcus faecalis growth in mammary secretions in the current trial and prevalence of naturally occurring IMI followed similar trends across the nonlactating and lactation periods (Todhunter et al., 1995). Conversely, E. faecium growth responses in mammary secretions measured in the pres- 
ent study differed markedly from rates of naturally occurring enterococcal IMI during the dry period and lactation (Todhunter et al., 1995). In summary, the differences in bacterial growth between the 2 species in the mammary secretion assays may indicate differences in susceptibility of mammary glands to $E$. faecalis and $E$. faecium during the lactation cycle. Differences observed between the species tested indicated that potential mastitis pathogens within the genus Enterococcus are not homogeneous; thus, critical control points during the lactation cycle and management practices to control mastitis by enterococci may need to be species-specific.

\section{REFERENCES}

Bannerman, D. D., M. J. Paape, J. P. Goff, K. Kimura, J. D. Lippolis, and J. C. Hope. 2004. Innate immune response to intramammary infection with Serratia marcescens and Streptococcus uberis. Vet. Res. 35:681-700.

Burvenich, C., V. Van Merris, J. Mehrzad, A. Diez-Fraile, and L. Duchateau. 2003. Severity of E. coli mastitis is mainly determined by cow factors. Vet. Res. 34:521-562.

Devriese, L. A., J. Hommez, H. Laevens, B. Pot, P. Vandamme, and F. Haesebrouck. 1999. Identification of aesculin-hydrolyzing streptococci, lactococci, aerococci and enterococci from subclinical intramammary infections in dairy cows. Vet. Microbiol. 70:87-94.

Devriese, L. A., L. Laurier, P. De Herdt, and F. Haesebrouck. 1992. Enterococcal and streptococcal species isolated from faeces of calves, young cattle and dairy cows. J. Appl. Bacteriol. 72:29-31.

Devriese, L. A., and B. Pot. 1995. The genus Enterococcus. Pages 327-367 in The Lactic Acid Bacteria. The Genera of Lactic Acid Bacteria. Vol. 2. B. J. B. Wood and W. H. Holzapfel, ed. Blackie Academic and Professional, London, UK.

Franz, C. M., M. E. Stiles, K. H. Schleifer, and W. H. Holzapfel. 2003. Enterococci in foods-A conundrum for food safety. Int. J. Food Microbiol. 88:105-122.

Godfree, A. F., D. Kay, and M. D. Wyer. 1997. Faecal streptococci as indicators of faecal contamination in water. J. Appl. Microbiol. $83: 110 \mathrm{~S}-119 \mathrm{~S}$.

Hayes, J. R., L. L. English, L. E. Carr, D. D. Wagner, and S. W. Joseph. 2004. Multiple-antibiotic resistance of Enterococcus spp. isolated from commercial poultry production environments. Appl. Environ. Microbiol. 70:6005-6011.

Hogan, J. S., and K. L. Smith. 2003. Coliform mastitis. Vet. Res. 34:507-519

Hogan, J. S., K. L. Smith, K. H. Hoblet, P. S. Schoenberger, D. A. Todhunter, W. D. Hueston, D. E. Pritchard, G. L. Bowman, L. E. Heider, B. L. Brockett, and H. R. Conrad. 1989. Field survey of mastitis in low somatic cell count herds. J. Dairy Sci. 72:15471556.

Hogan, J. S., W. P. Weiss, K. L. Smith, D. A. Todhunter, P. S. Schoenberger, and L. M. Sordillo. 1995. Effects of an Escherichia coli J5 vaccine on mild clinical coliform mastitis. J. Dairy Sci. 78:285290.

Huycke, M. M., D. F. Sahm, and M. S. Gilmore. 1998. Multiple-drug resistant enterococci: The nature of the problem and an agenda for the future. Emerg. Infect. Dis. 4:239-249.

Lin, J., J. S. Hogan, and K. L. Smith. 1998. Inhibition of in vitro growth of coliform bacteria by a monoclonal antibody directed against ferric enterobactin receptor FepA. J. Dairy Sci. 81:1267-1274.

Lohuis, J. A., W. Kremer, Y. H. Schukken, J. A. Smit, J. H. Verheijden, A. Brand, and A. S. Van Miert. 1990. Growth of Escherichia coli in milk from endotoxin-induced mastitic quarters and the course of subsequent experimental Escherichia coli mastitis in the cow. J. Dairy Sci. 73:1508-1514.

McDonald, T. J., and J. S. McDonald. 1976. Streptococci isolated from bovine intramammary infections. Am. J. Vet. Res. 37:377-381.

National Mastitis Council. 1996. Current Concepts of Bovine Mastitis. 4th ed. NMC Inc., Verona, WI.

NNIS Report. 1997. National nosocomial infections surveillance (NNIS) report, data summary from October 1986-April 1997. Am. J. Infect. Contr. 25:477-487.

Oliver, S. P., and V. K. Juneja. 1990. Growth of Corynebacterium bovis in mammary secretions during physiological transitions of the bovine mammary gland. J. Dairy Sci. 73:351-356.

Oliver, S. P., V. K. Juneja, and R. J. Harmon. 1990. Influence of nonlactating and peripartum bovine mammary secretions on growth of Staphylococcus species. J. Dairy Sci. 73:995-999.

Paape, M. J., D. D. Bannerman, X. Zhao, and J. W. Lee. 2003. The bovine neutrophil: structure and function in blood and milk. Vet. Res. 34:597-627.

Sobiraj, A., A. Kron, U. Schollmeyer, and K. Failing. 1997. Federal investigations on the distribution and in vitro resistance of udder pathogenic bacteria in the milk of cows with subclinical mastitis. Tierarztl. Prax. 25:108-115.

Sordillo, L. M., K. Shafer-Weaver, and D. DeRosa. 1997. Immunobiology of the mammary gland. J. Dairy Sci. 80:1851-1865.

Tenhagen, B.-A., G. Koster, J. Wallmann, and W. Heuwieser. 2006. Prevalence of mastitis pathogens and their resistance against antimicrobial agents in dairy cows in Brandenburg, Germany. J. Dairy Sci. 89:2542-2551.

Todhunter, D., K. L. Smith, and J. S. Hogan. 1990. Growth of gramnegative bacteria in dry cow secretion. J. Dairy Sci. 73:363-372.

Todhunter, D. A., K. L. Smith, and J. S. Hogan. 1995. Environmental streptococcal intramammary infections of the bovine mammary gland. J. Dairy Sci. 78:2366-2374.

Todhunter, D. A., K. L. Smith, and P. S. Schoenberger. 1985. In vitro growth of mastitis-associated streptococci in bovine mammary secretions. J. Dairy Sci. 68:2337-2346.

Weaver, R. W., J. A. Entry, and A. Graves. 2005. Numbers of fecal streptococci and Escherichia coli in fresh and dry cattle, horse, and sheep manure. Can. J. Microbiol. 51:847-851. 